\title{
The Structure of the Dust Layer over the Taklimakan Desert during the Dust Storm in April 2002 as Observed Using a Depolarization Lidar
}

\author{
Kenji KAI, Yuichi NAGATA, Nobumitsu TSUNEMATSU ${ }^{1}$ \\ Graduate School of Environmental Studies, Nagoya University, Nagoya, Japan \\ Takatsugu MATSUMURA \\ Graduate School of Science, Fukuoka University, Fukuoka, Japan \\ Heon-Sook KIM, Takuya MATSUMOTO ${ }^{2}$ \\ Graduate School of Environmental Studies, Nagoya University, Nagoya, Japan
}

Shunjun HU, Hongfei ZHOU

Xinjiang Institute of Ecology and Geography, Chinese Academy of Sciences, Urumqi, China

Makoto ABO

Graduate School of System Design, Tokyo Metropolitan University, Tokyo, Japan

and

Tomohiro NAGAI

Meteorological Research Institute, JMA, Tsukuba, Japan

(Manuscript received 27 September 2004, in final form 30 July 2007)

\begin{abstract}
In April 2002, a severe dust storm occurred in the Taklimakan Desert. A large amount of the dust was lifted up by the dust storm and gradually removed in the following few days. The whole event of the dust storm was observed by the Mie-scattering depolarization lidar at Aksu, Xinjiang, China $\left(40.62^{\circ} \mathrm{N}, 80.83^{\circ}\right.$ E, $1028 \mathrm{~m}$ above mean sea level). This paper describes the dust event and the removal process that was observed by the lidar.

During the dust storm (April 13-16), a dense dust layer developed from the ground up to $5.5 \mathrm{~km}$. The backscattering ratio was 20 or more, and the depolarization ratio was $15-25 \%$. Due to the absorption of the laser beam by the heavy dust, a normal lidar observation was impossible for several hours. In this study, we estimated the backscattering ratio at the lowest height during the dust storm by solving the lidar equation directly.

After the dust storm (April 17-20), a clear diurnal variation of the top of the dust layer was found by the lidar. An investigation of the lidar signals at different heights shows that there were two types of the removal process of the dust. The lidar signals at lower heights (less than the $2 \mathrm{~km}$ ) gradually decreased during the post-dust storm period. This result indicates that the gravitational settling of the relatively large
\end{abstract}


sized dust (coarse particles with a diameter of $10 \mu \mathrm{m}$ or more) occurs near the ground. On the other hand, lidar signals at $2-4 \mathrm{~km}$ had a clear diurnal variation with spike-like peaks from evening to midnight. These peaks suggest that the advection of the relatively small sized dust picked up in other location is due to the local circulation that occurs in the Tianshan Mountains and Tarim Basin.

\section{Introduction}

During the spring in East Asia, dust storms lift a large amount of mineral dust into the atmosphere, which is known as Asian dust or Kosa. In 2000-2002, dust storms occurred frequently in Northern China, the Korean Peninsula, and Japan (Kurosaki and Mikami 2003) and caused a wide range of effects in East Asia. They not only pose serious health and transportation hazards, but also have an effect on the radiation and cloud physics in East Asia (UNCCD, 2001).

The Taklimakan Desert is one of the most important sources of Asian dust (Fig. 1). It is located in the Tarim Basin, which is surrounded by Tianshan Mountains in north, Pamir Plateau in west, and Kunlun Mountains in south, exceeding an altitude of $4000 \mathrm{~m}$. The Asian dust, when lifted up to the free troposphere, can be transported over long distances (Duce et al. 1982; Iwasaka et al. 1983; Kai et al. 1988) and can have global affects. In fact, Iwasaka et al. (1988) have shown that Asian dust originating in the Taklimakan Desert plays an important role in causing global effects.

Since their inception in 2000, the Japan-China Joint Studies on Origin and Transport of Aeolian Dust and its Impact on Climate (ADEC) group has examined the transport mechanism of mineral dust from arid regions, mainly the Taklimakan Desert and its surrounding areas, into the atmosphere (Mikami et al. 2006). Seino et al. (2005) studied the mesoscale circulations in the Tarim Basin associated with dust events. Uno et al. (2005) showed that the meteorological characteristics and dust distribution of the Tarim Basin can be simulated using a regional dust model. Tsunematsu et al. (2005a) have investigated the effects of

Corresponding author: Kenji Kai, Graduate School of Environmental Studies, Nagoya University, Furocho, Chikusa-ku, Nagoya 464-8601, Japan

E-mail: kai@info.human.nagoya-u.ac.jp

1 Present affiliation: National Institute of Information and Communications Technology

2 Present affiliation: Hamamatsu Photonics K.K. (C)2008, Meteorological Society of Japan the Tianshan Mountains on the height of the dust layer in the Taklimakan desert. Furthermore, based on lidar observations, Tsunematsu et al. (2005b) noted an extensive dust outbreak following the breakup of the morning inversion in the Taklimakan Desert. Iwasaka et al. (2003) made balloon and lidar observations at Dunhuang, China, which is located at the exit of the Taklimakan Desert. This allowed them to infer the characteristics of the dust originating from the Taklimakan Desert.

In studies that deal with Asian dust, one of the most important parameters in understanding aerosol transport is the vertical distribution of the Asian dust over the source regions. Satellite imagery has allowed the regional and global distribution of aerosols and their impact on climate to be studied. However, satellite measurements, excluding space lidars (CALIPSO and GLAS), are passive and do not provide information on the altitude distribution of the aerosols (Vaughan et al. 2004; Spinhirne et al. 2006). Furthermore, it should be noted that the long-range transport of dust is highly dependent on vertical mixing.

As part of ADEC, a new lidar was developed and installed at Aksu in the Taklimakan Desert. In April 2002, during ADEC's intensive observation period (IOP), strong dust storms were observed after a trough passed over Aksu. Tsunematsu (2005) reported on the onset of this dust storm. Due to the absorption of the laser beam by the heavy dust, lidar observations during the dust storm were impossible for several hours. In this study, we estimate the backscattering ratio at the lowest height during the dust storm by directly solving the lidar equation. In addition, the removal process of the dust from the source region is discussed. This paper describes the lidar system, as well as the dust storm event and its removal process over the Taklimakan Desert during the IOP of 2002.

\section{Lidar system}

\subsection{System design and configuration}

We developed an all-weather type lidar system to continuously measure the vertical distribution 


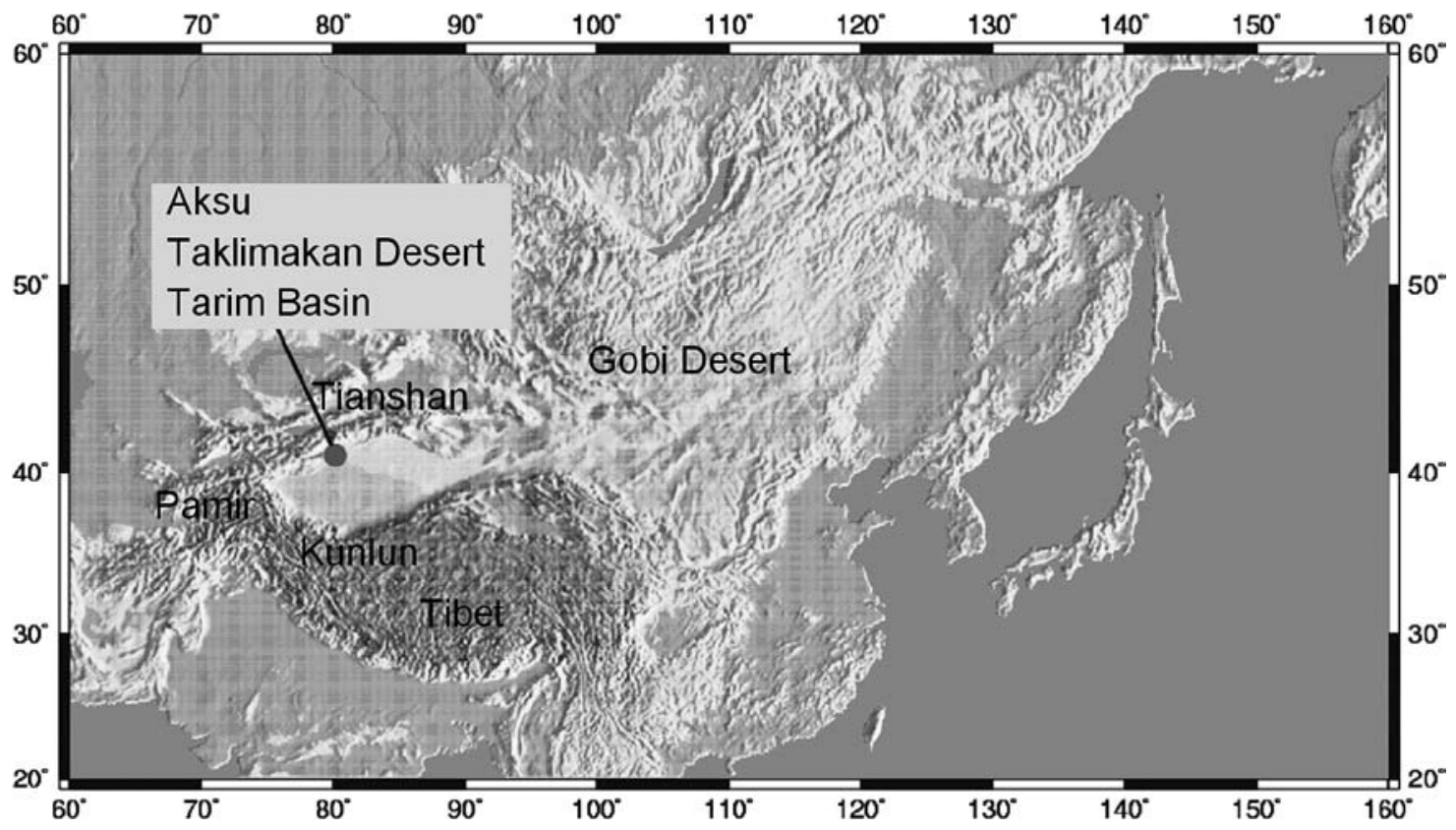

Fig. 1. Location of the Taklimakan Desert and Aksu $\left(40^{\circ} 37^{\prime} \mathrm{N}, 80^{\circ} 50^{\prime} \mathrm{E}, 1028 \mathrm{~m}\right.$ above sea level), Xinjiang, China. The Tarim Basin is surrounded by the Tianshan Mountains, the Pamir Plateau, and the Kunlun Mounatins.

of the dust from the atmospheric boundary layer through the troposphere up to the stratosphere over the Taklimakan Desert. The vertical distribution of the desert dust has two characteristics; one is a dense dust layer in the atmospheric boundary layer, and the second is a steep gradient of the dust from the atmospheric boundary layer to the lower troposphere (= relatively clean layer). To meet two conditions, the lidar must have a wide dynamic range for measuring the backscattering from the dust at three different layers. Thus, we prepared three channels of photomultiplier tubes (PMT); one for the atmospheric boundary layer, the second one for the troposphere and the third one for the stratosphere.

Figures 2 and 3 show the photographs, illustrations, and a block diagram of the lidar system. Table 1 lists the specification of the lidar. The lidar system is a single wavelength Nd:YAG laserbased system designed to measure the vertical profiles of backscattering and depolarization ratios of aerosol particles from the layer near the ground up to the stratosphere. The preliminary test observations using the lidar in Japan have been previously presented by Kai et al. (2002).

A pulsed Nd:YAG laser was employed as the transmitter. The green line in the illustration is a laser beam transmitted from the Nd:YAG laser. The pulse energy of the laser was $300 \mathrm{~mJ}$ at $532 \mathrm{~nm}$, and the pulse frequency was $10 \mathrm{~Hz}$. To expand the receiving range and signal strength, two telescopes were used: one with a diameter of $200 \mathrm{~mm}$ to measure the lower atmosphere, and another with a diameter of $355 \mathrm{~mm}$ to measure the upper atmosphere. The smaller telescope and transmitting laser light were aligned coaxially, in order to measure the aerosol layer in the lowest altitude range. The larger telescope was set parallel to the smaller telescope.

In the small telescope, two photomultiplier tubes were used as detectors to receive the parallel (P) and perpendicular (S) components needed to measure the depolarization ratio. The depolarization ratio is an important parameter that helps to determine the degree to which the particles are not spherical. The subscript, 20 , is used to denote the signal from the small telescope of the PMT.

The light received by the larger telescope was separated into parallel and perpendicular components. The parallel component was further split into 2 channels to increase the observable range 

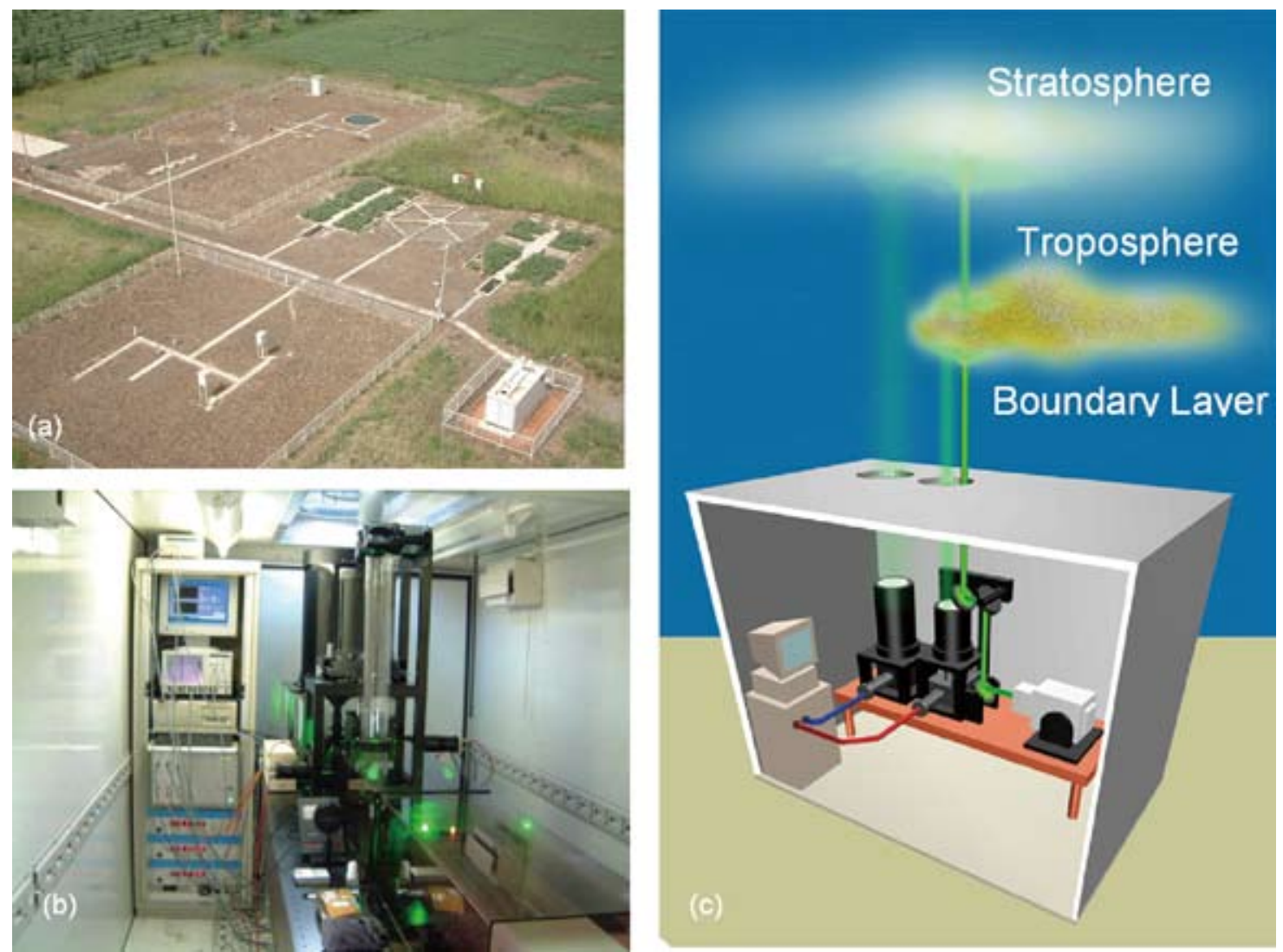

Fig. 2. Photographs and illustration of the lidar system. (a) Aksu Water Balance Experimental Station, Xinjiang Institute of Ecology and Geography, CAS. (b) Inside of the lidar container. (c) Illustration of the lidar system.

of altitudes. The ratio of the signal strength of the 2 parallel channels $(P(90 \%)$ and $P(10 \%))$ was $9: 1$, so that the dynamic range of the received signal was increased 10 times. An electrical gate circuit was added to the higher altitude channel $P(90 \%)$ to remove noise from the strong ground signals. A PMT signal with the electrical gate and a transparency of $90 \%$ was used to measure the stratosphere. This signal is denoted by the subscript, $35 \mathrm{H}$. A PMT signal with a transparency of $10 \%$ was used to measure the troposphere. This signal is denoted by the subscript, ${ }_{35 L}$. A 12-bit A/ $\mathrm{D}$ converter and a photon counting system were also used in the upper receiver to expand the dynamic range of the signals. Using these 3 parallel and 2 perpendicular channels, as well as the A/D conversion and photon counting systems, the lidar system can measure a range of altitudes from close to the surface all the way up to the stratosphere (30 km and above).
All of the instruments, including the optical components, data processing instruments, and electronics, were housed in an environmental shelter (container). Two optical windows were set in the ceiling of the shelter to protect the field of view of the two telescopes. Each optical window had two coated optical glass plates to prevent the formation of dew or frost.

During the IOP, the pulse repetition was $10 \mathrm{~Hz}$. A series of 3,000 laser pulses were averaged to get 5 minute-mean vertical profiles of the backscattering and depolarization ratios. The height resolution of the lidar was $75 \mathrm{~m}$, which was obtained by averaging 10 consecutive vertical data points (Table 1). Based on the configuration of the lidar, the lowest height that could be measured was $187 \mathrm{~m}$.

\subsection{Lidar equations}

The following equations are used in the study: 


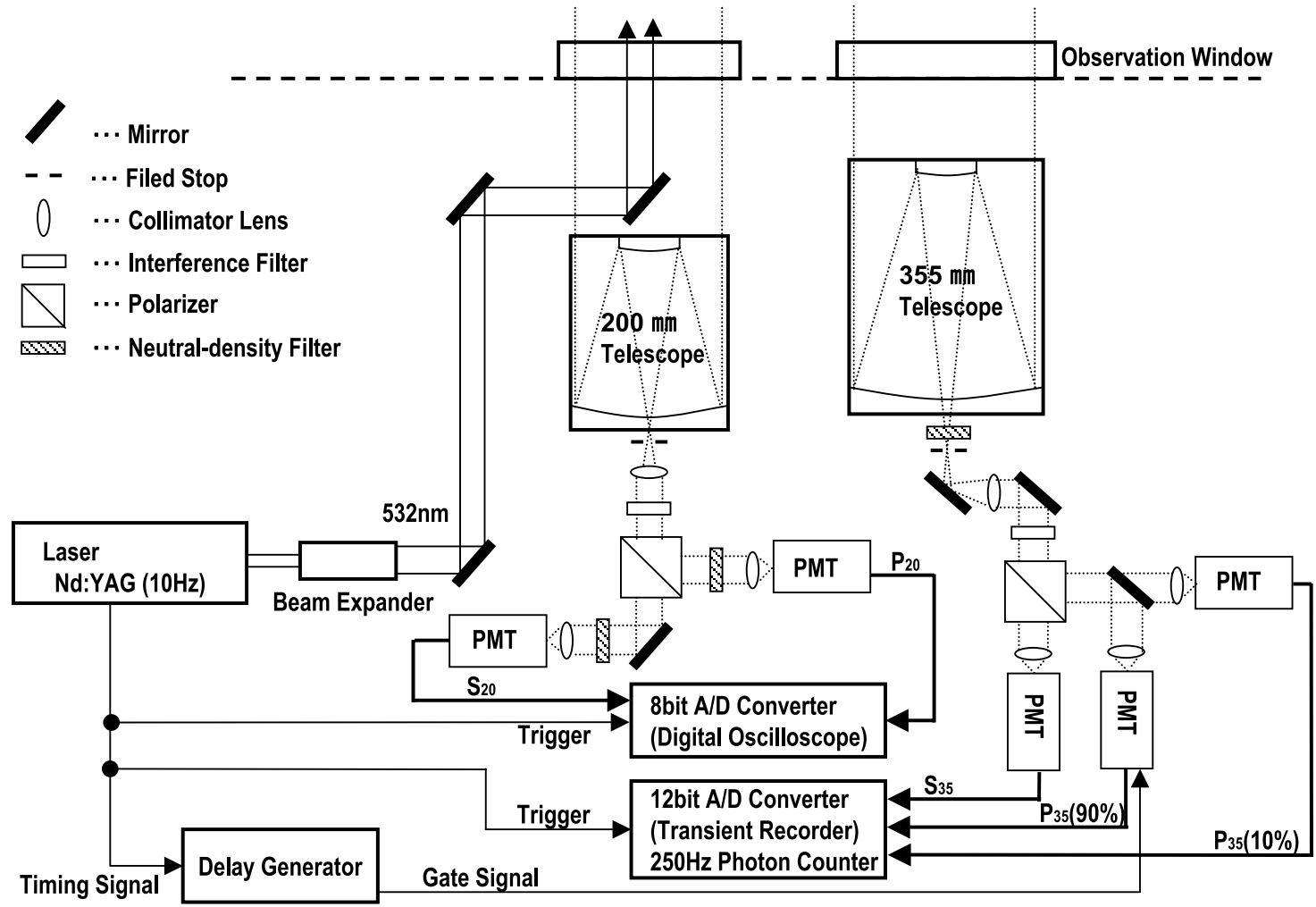

Fig. 3. Block diagram of the lidar system. PMT: Photomultiplier, P and S: parallel and perpendicular components with respect to the polarization plane of the emitted laser, $\mathrm{P}(90 \%)$ and $\mathrm{P}(10 \%)$ are parallel components with transparency of $90 \%$ and $10 \%$.

Table 1. Specification of the lidar system

\begin{tabular}{|c|c|c|}
\hline $\begin{array}{l}\text { Transmitter } \\
\text { Laser } \\
\text { Wavelength } \\
\text { Pulse energy } \\
\text { Repetition rate } \\
\text { Beam } \\
\text { divergence }\end{array}$ & $\begin{array}{l}\text { Nd:YAG Laser } \\
532 \mathrm{~nm} \\
300 \mathrm{~mJ} \\
10 \mathrm{~Hz} \\
0.2 \mathrm{mrad}\end{array}$ & \\
\hline Receiver & Lower & Upper \\
\hline Telescope & $\begin{array}{l}\text { Schmidt- } \\
\text { Cassegrain }\end{array}$ & $\begin{array}{l}\text { Schmidt- } \\
\text { Cassegrain }\end{array}$ \\
\hline $\begin{array}{l}\text { Diameter } \\
\text { Geometry }\end{array}$ & $\begin{array}{l}200 \mathrm{~mm} \\
\text { coaxial }\end{array}$ & $\begin{array}{l}355 \mathrm{~mm} \\
\text { parallel }\end{array}$ \\
\hline Filed of view & $3 \mathrm{mrad}$ & $1 \mathrm{mrad}$ \\
\hline Polarization & $\mathrm{P}, \mathrm{S}$ & $\begin{array}{l}\text { P10 (lower), } \\
\text { P90 (Upper), S }\end{array}$ \\
\hline Detector & PMT (2) & PMT (3) \\
\hline Range resolution & $7.5 \mathrm{~m}(50 \mathrm{~ns})$ & $7.5 \mathrm{~m}(50 \mathrm{~ns})$ \\
\hline Data processing & $\mathrm{A} / \mathrm{D}(8 \mathrm{bit} / 2002)^{*}$ & $\begin{array}{l}\text { A/D (12 bit) and } \\
\text { Photon counting } \\
\text { ( } 250 \mathrm{MHz})\end{array}$ \\
\hline
\end{tabular}

1) The lidar equation:

$$
P(z)=\frac{K}{z^{2}}\left[\beta_{m}(z)+\beta_{a}(z)\right] T(0, z)
$$

2) Atmospheric transmittance:

$$
T(0, z)=\exp \left\{-2 \int_{0}^{z}\left(\sigma_{m}\left(z^{\prime}\right)+\sigma_{a}\left(z^{\prime}\right)\right) d z^{\prime}\right\}
$$

3) Backscattering ratio:

$$
\begin{aligned}
R(z)= & \frac{\beta_{m}(z)+\beta_{a}(z)}{\beta_{m}(z)} \\
= & R\left(z^{*}\right) \frac{n_{d}\left(z^{*}\right) P(z) z^{2}}{n_{d}(z) P\left(z^{*}\right) z^{* 2}} \\
& \cdot \exp \left[-2 \int_{z}^{z^{*}}\left\{\sigma_{m}\left(z^{\prime}\right)+\sigma_{a}\left(z^{\prime}\right)\right\} d z^{\prime}\right]
\end{aligned}
$$

4) Lidar ratio:

$$
\sigma_{a}(z)=S_{1} \beta_{a}(z)
$$

* 12 bit after 2003. 
(a) High range:

Stratosphere

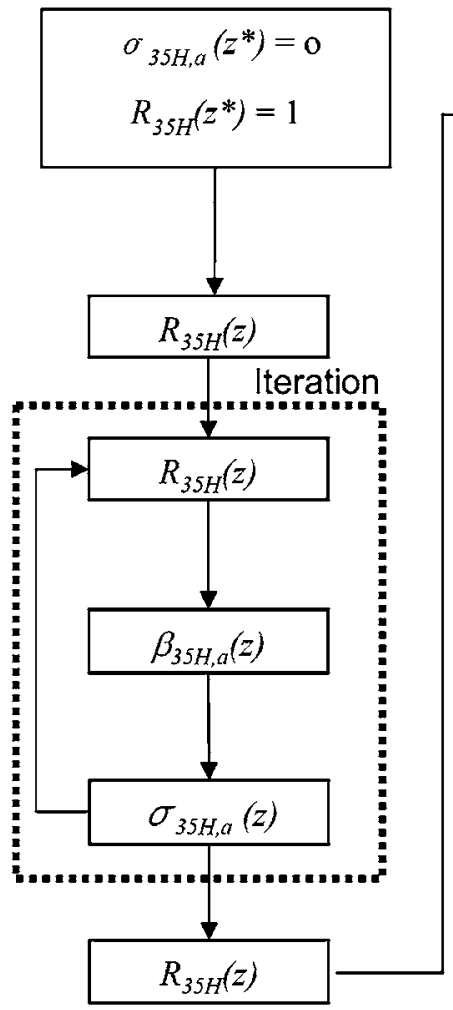

(b) Middle range:

Troposphere

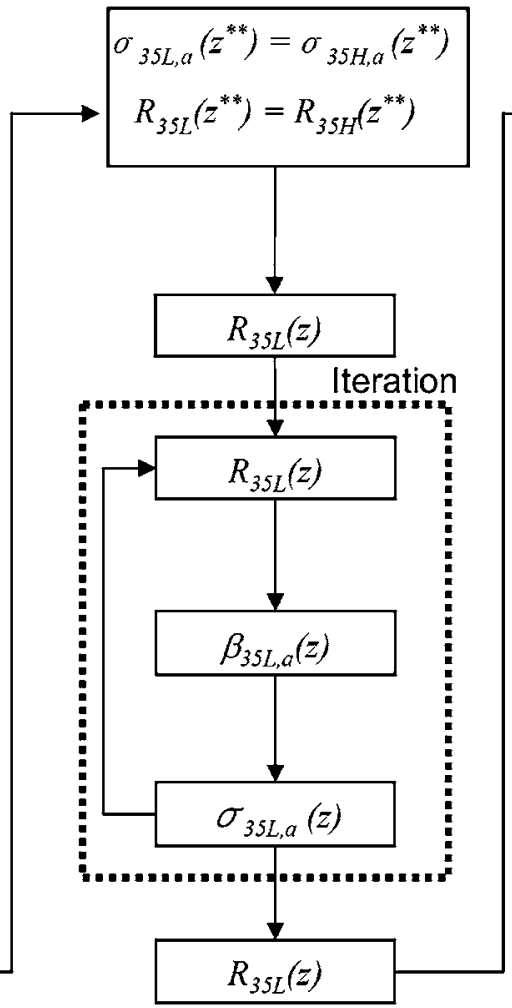

(c) Low range:

\section{Atmospheric boundary layer}

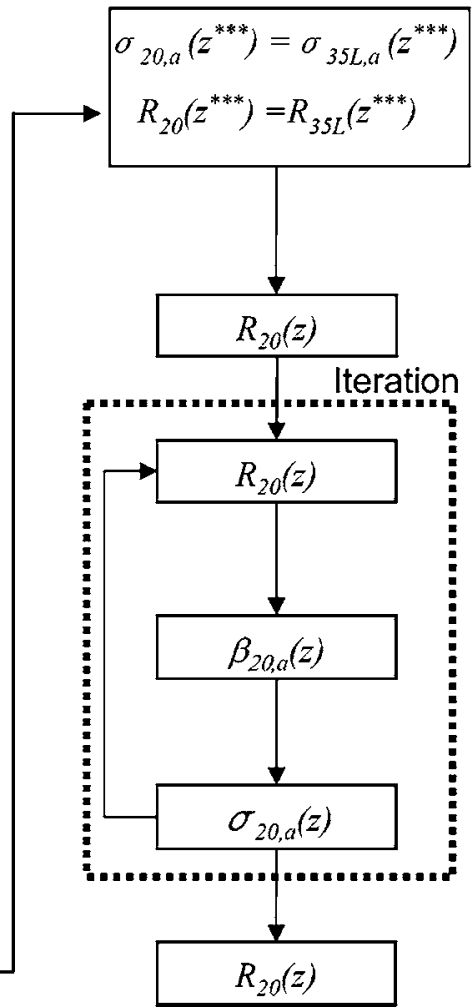

Fig. 4. Data processing of the lidar data.

5) Total depolarization ratio:

$$
\begin{aligned}
\delta_{t}(z) & \equiv \frac{\beta_{a, \perp}(z)+\beta_{m, \perp}}{\beta_{a, / /}(z)+\beta_{m, / /}+\beta_{a, \perp}(z)+\beta_{m, \perp}} \times 100[\%] \\
& =\frac{g P_{\perp}(z)}{P_{/ /}(z)+g P_{\perp}(z)} \times 100[\%]
\end{aligned}
$$

where $z$ is the height above the ground; $P(z)$ is the signal from the height, $z ; K$ is a lidar constant; $\beta(z)$ is the backscattering coefficient; $\sigma(z)$ is the extinction coefficient; $T(0, z)$ is the atmospheric transmittance; $R(z)$ is the backscattering ratio; $z^{*}$ is the normalizing height; $n_{d}(z)$ is the molecular density from the U.S. Standard Atmosphere; $\delta t(z)$ is the total depolarization ratio; $g$ is the signal gain; $S_{1}$ is the lidar ratio; subscript $a$ refers to the aerosol particles, subscript $m$ refers to the air molecules, the subscript // refers to the parallel component and the subscript $\perp$ refers to the perpendicular component with respect to the polarization plane of the emitted laser. The lidar ratio $S_{1}$ of 35 was assumed in this study (Yasui et al. 2005).

\subsection{Data processing}

Since there is plenty of dust in the atmospheric boundary layer, and an aerosol-free layer can rarely be found, the calibration of the lidar signal is usually difficult. To overcome this problem, we processed the lidar data from the stratosphere to the atmospheric boundary layer using the procedure shown in Fig. 4.

Firstly, we assumed that there was an aerosolfree layer in the stratosphere where the extinction coefficient of the aerosol was zero:

$$
\sigma_{35 H, a}\left(z^{*}\right)=0 \text { and } R_{35 H}\left(z^{*}\right)=1
$$

where $z^{*}$ is the normalizing height (about $15 \mathrm{~km}$ ), $\sigma_{35 H, a}$ is the extinction coefficient of the aerosol, and $R_{35 H}$ is the backscattering ratio in the strato- 
sphere, the subscript, ${ }_{35 H}$, refers to the PMT signal obtained from the larger telescope with a diameter of $355 \mathrm{~mm}$ and transparency of $90 \%$ as shown in Fig. 3.

An iterative technique developed by Ismail et al. (2000) was employed in this study. The iterative technique has two assumptions: (1) that a known relationship existed between aerosol backscatter and extinction, and (2) that this relationship was constant over the entire aerosol layer under consideration.

Based on the initial assumption given as Eq. (6), $R_{35 H}(z)$ was iteratively calculated at the following steps:

(i) The backscattering ratio $R_{35 H}(z)$ was calculated by Eq. (3).

(ii) Using $R_{35 H}(z)$, the backscattering coefficient of the aerosol $\beta_{35 H, a}(z)$ was calculated by Eq. (7).

$$
\beta_{35 H, a}(z)=\beta_{m}(z)\left(R_{35 H}(z)-1\right)
$$

(iii) Using $\beta_{35 H, a}(z)$, the extinction coefficient of the aerosol $\sigma_{35 H, a}(z)$ was calculated by Eq. (4) with the assumption of a constant lidar ratio $\left(S_{1}\right.$ $=35)$.

(iv) Returning to the step (i), $R_{35 H}(z), \beta_{35 H, a}(z)$, and $\sigma_{35 H_{, a}}(z)$ were obtained by the iteration from (i) to (iii). The iteration was terminated as the values of $\beta_{35 H, a}(z)$ was converged. The number of the iteration was 20 times.

Secondly, the value of $R_{35 H}(z)$ at $z=z^{* *}$ (about $10 \mathrm{~km}$ ) was used in calculating the values for the troposphere:

$$
\sigma_{35 L, a}\left(z^{* *}\right)=\sigma_{35 H, a}\left(z^{* *}\right) \text { and } R_{35 L}\left(z^{* *}\right)=R_{35 H}\left(z^{* *}\right)
$$

where $z^{* *}$ is the connecting height (about $10 \mathrm{~km}$ ) between high and middle ranges as shown in Fig. $4, \sigma_{35 L, a}$ is the extinction coefficient of the aerosol, and $R_{35 L}$ is the backscattering ratio in the troposphere. The subscript, ${ }_{35}$, refers to the PMT signal obtained from the larger telescope with a diameter of $355 \mathrm{~mm}$ and transparency of $10 \%$ as shown in Fig. 3.

Thirdly, the value of $R_{35 L}(z)$ at $z=z^{* * *}$ (about 3 $\mathrm{km}$ ) was used in calculating the values for the atmospheric boundary layer:

$$
\sigma_{20, a}\left(z^{* * *}\right)=\sigma_{35 L, a}\left(z^{* * *}\right) \text { and } R_{20}\left(z^{* * *}\right)=R_{35 L}\left(z^{* * *}\right)
$$

where $z^{* * *}$ is a connecting height (about $3 \mathrm{~km}$ ) between the middle and low ranges as shown in Fig. 4, $\sigma_{20, a}$ is the extinction coefficient of the aerosol, and $R_{20}$ is the backscattering ratio in the atmospheric boundary layer. The subscript, ${ }_{20}$, refers to the PMT signal obtained from the smaller telescope with a diameter of $200 \mathrm{~mm}$ as shown in Fig. 3.

Finaly, a composite profile of the backscattering ratio covering the atmospheric boundary layer, the troposphere, and the stratosphere was obtained based on $R_{35 H}(z), R_{35 L}(z)$, and $R_{20}(z)$.

\subsection{Observation site}

Lidar observations were carried out at the Aksu Water Balance Experimental Station of the Xinjiang Institute of Ecology and Geography, Chinese Academy of Sciences, located in the northern part of the Taklimakan Desert $\left(40^{\circ} 37^{\prime} \mathrm{N}, 80^{\circ} 50^{\prime} \mathrm{E}\right.$, $1028 \mathrm{~m}$ above mean sea level) in China (Fig. 1). The Aksu Station is situated in an oasis, $80 \mathrm{~km}$ southeast of the Aksu city. The data of the routine meteorological observation, automated meteorological instruments and aerosol sampling in the experimental field were available (Yabuki et al. 2005). The lidar observations were continuously conducted from April 11 to 21, 2002 except several power failures.

\section{Results and discussion}

In the spring of 2002, due to the strong surface winds and dry surface conditions, dust storm activity was very high in East Asia (Kurosaki and Mikami 2003). The intensive observation period (IOP) in the Japan-China Joint Studies on Origin and Transport of Aeolian Dust and its Impact on Climate (ADEC) was carried out during April 1121, 2002. Strong dust storms occurred on April 13-16, when a trough passed over Aksu. After the dust storms, the dense dust layer developed from the ground to several kilometers above the surface.

\subsection{Synoptic and surface meteorological conditions}

Figure 5 shows a $500 \mathrm{hPa}$ weather map for 0000 UTC on April 14. A thick solid line in the figure indicates the trough. After the passage of the trough on April 13, a strong easterly wind caused a severe dust storm on April 13-16, 2002 in Aksu.

We try to simulate the surface wind distribution around the Taklimakan Desert at 1800 UTC on April 13, 2002 by MM5, the fifth-generation mesoscale model of non-hydrostatic version 3 (Pennsylvania State University/National Center 




Fig. 5. $500 \mathrm{hPa}$ weather map around the Taklimakan Desert at $0000 \mathrm{UTC}$ obtained on April 14, 2002. The arrows indicate the wind vector. The solid lines indicate the geopotential height (in $\mathrm{m}$ ) at an interval of $40 \mathrm{~m}$. The thick straight line indicates the axis of a trough.

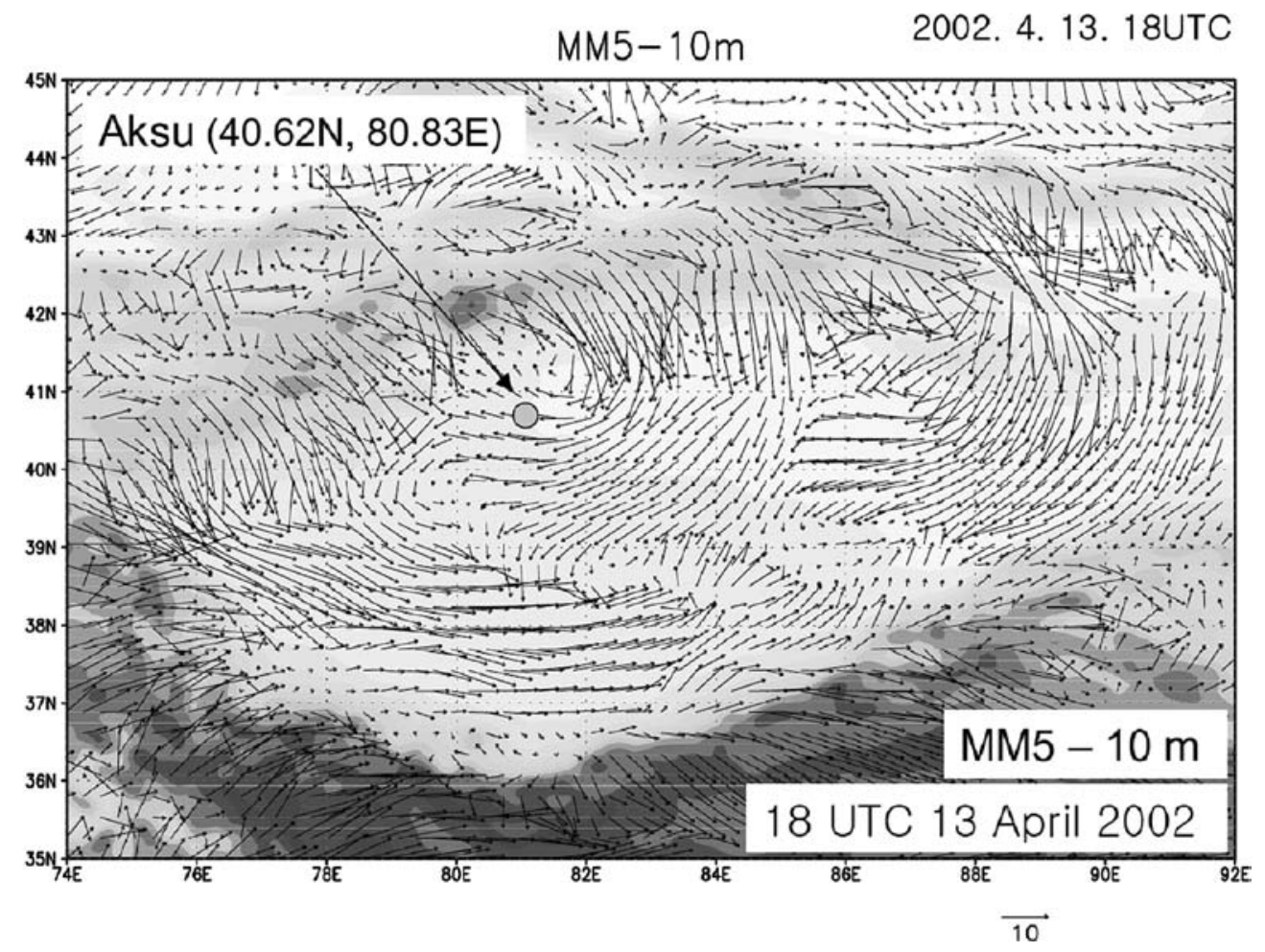

Fig. 6. Surface wind field around the Taklimakan Desert at a height of $10 \mathrm{~m}$ at 18:00 UTC on April 13, 2002, as simulated by MM5. The arrows indicate the wind vector. 
for Atmospheric Research), defined in the $\mathrm{x}, \mathrm{y}$ and $\sigma$-coordinate (Grell et al. 1995). National Centers for Environment Prediction/National Center for Atmospheric Research (NCEP/NCAR) 6-hourly reanalysis data were interpolated linearly into the outermost coarse-mesh lateral boundary conditions. Three levels of two-way nested domain were used with grid resolutions of $108 \mathrm{~km}, 36$ $\mathrm{km}$ and $12 \mathrm{~km}$. The total of 30 sigma-levels in the vertical direction was used, with the model top at $100 \mathrm{hPa}$. As shown in Fig. 6 with a grid resolution of $12 \mathrm{~km}$, the easterly wind was separated from the synoptic-scale cold westerly wind and intruded into the Taklimakan Desert after going around the eastern side of the Tianshan Mountains. The easterly wind brought the dust storm in Aksu.

Figure 7 shows a time series of meteorological elements during April 10-21, 2002, while Fig. 8 shows photos of the area before, during, and after the dust storm. A dust outbreak occurred at 1430 LST on April 13 on the experimental field in Aksu, just after the trough passed over Aksu in the morning of April 13 (Fig. 7a). A strong and steady easterly wind was predominant during April 13 and 16 (Fig. 7c). The simulated horizontal distribution of the easterly wind is shown in Fig. 6. The dust storm led to a sudden change in visibility and other surface meteorological conditions (Fig. 7b). The visibility before the dust storm had been fine and was more than $40 \mathrm{~km}$ (Fig. $8 \mathrm{a}$ ). Four hours before the dust storm, middle to high clouds appeared over Aksu (Fig. 8b). These clouds descended, and then a dust storm occurred at the surface (Fig. 8c). Subsequently, the visibility decreased to less than $1 \mathrm{~km}$.

As shown in Table 2, the observation period during April 11-21 can be divided into the following 3 stages:

(1) BD: before the dust storm on April 11 and 12. The visibility was good (more than 40 $\mathrm{km})$. The wind speed was light (1-4 $\mathrm{m} \mathrm{s}^{-1}$ ) and steady (SW). The temperature had a diurnal variation with a maximum temperature of $26^{\circ} \mathrm{C}$.

(2) DS: during the dust storm. When the trough passed over the Tarim Basin, the pressure decreased and reached a minimum value in the morning of April 13. The wind direction became easterly with the wind speed abruptly reaching more than $6 \mathrm{~m} \mathrm{~s}^{-1}$. Visibility was less than $1 \mathrm{~km}$. The temperature decreased to $10^{\circ} \mathrm{C}$. The diur-



Fig. 7. Surface meteorological elements during the passage of the dust storm on April 11-21, 2002. (a) Atmospheric pressure, (b) visibility, (c) wind direction, (d) wind speed, and (e) temperature. The trough and period of the dust storm are indicated in the figure. The symbol, indicates a wind speed greater than $6 \mathrm{~m}$ $\mathrm{s}^{-1}$.

nal variation in temperature decreased due to the presence of heavy dust. The steady easterly wind continued from April 13 to 16.

(3) $\mathrm{AD}$ : after the dust storm. Once more, the wind speed decreased and the temperature increased. The temperature, wind direction and dust layer height exhibited clear diurnal variations. The wind direction exhibited a diurnal variation changing from northerly to westerly to southerly and finally to easterly. The backscattering ratio had a large value in the easterly direction, and a smaller value in the other directions (shown 

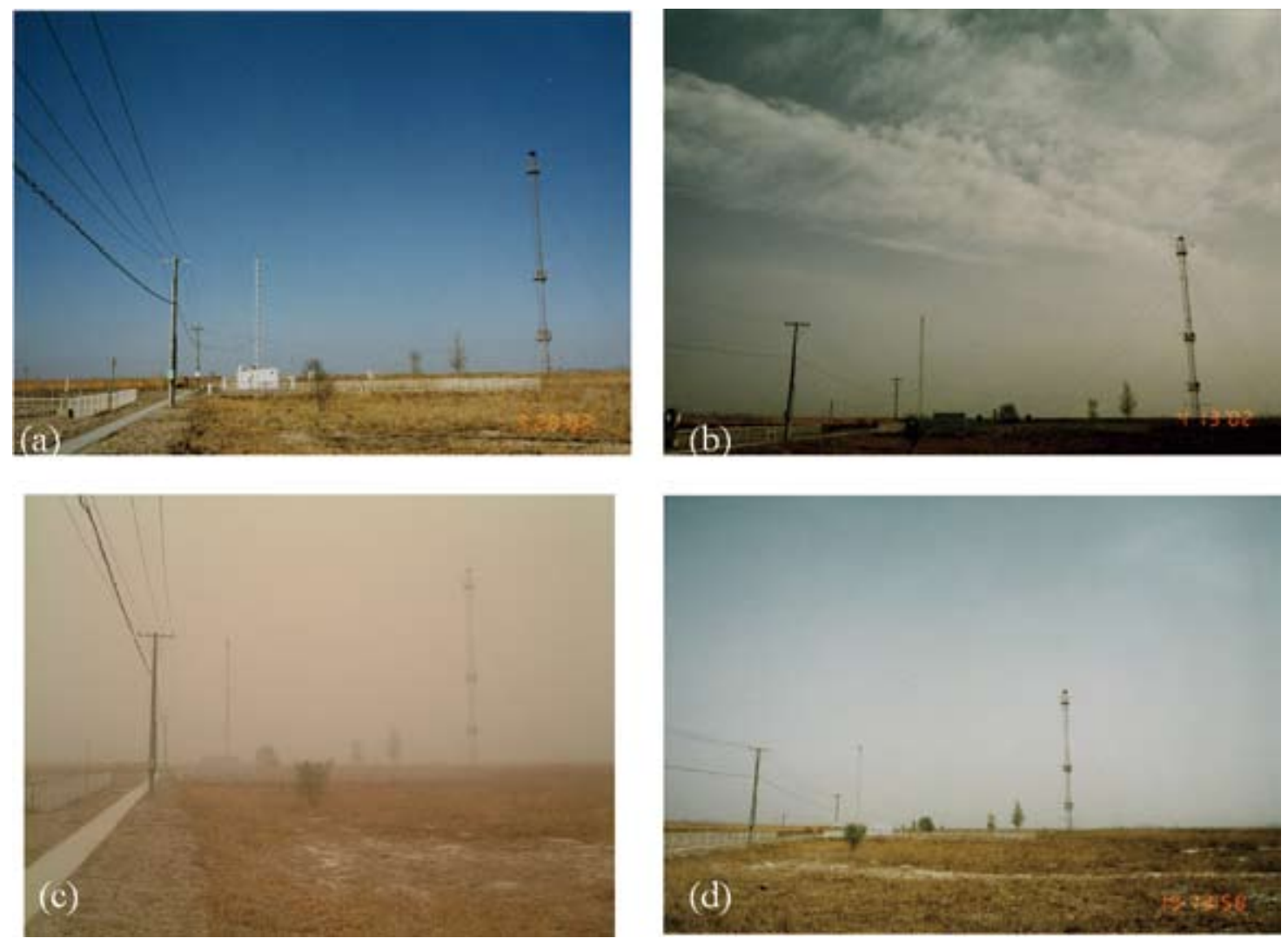

Fig. 8. Photographs before, during, and after the dust storm. (a) March 28, 2002: clear background conditions with good visibility. (b) 1025 LST on April 13, 2002: just before the dust storm. The upper clouds were descending. (c) April 15, 2002: severe dust storm. The visibility was between 100 and $200 \mathrm{~m}$. (d) April 19, 2002: after the dust storm. The diurnal variation and removal process were observed.

Table 2. Summary of Lidar Observations at Aksu, Xinjiang, China in April 2002

\begin{tabular}{llll}
\hline & Before dust storm & \multicolumn{1}{c}{ During dust storm } & \multicolumn{1}{c}{ After dust storm } \\
\hline Period & 10-12 April & 13-16 April & 17-20 April \\
Weather & Clear & Dust storm & Clear \\
Visibility & good $(40 \mathrm{~km})$ & Very bad $<1 \mathrm{~km}$ & bad $(8-35 \mathrm{~km})$ \\
Wind direction & around SW & Steady easterly wind & Diurnal variation \\
Wind speed & Light & Strong & Light \\
& & Peak wind speed $>6 \mathrm{~m} / \mathrm{s}$ & \\
Temperature & High & Low & High \\
Dust layer height & $3-4 \mathrm{~km}$ & $5.5 \mathrm{~km}$ & $2.5-5.5 \mathrm{~km}$ with a diurnal variation \\
$R(z)$ & $4-8$ & 20 or more & $5-20$ \\
$\delta t(z)$ & $8-10 \%$ & $15-25 \%$ & $13-20 \%$ \\
\hline
\end{tabular}

in Fig. 9).

From April 13-16, the dust event was characterized by the strong easterly wind. In this study, this period is defined as the dust storm period (DS).

\subsection{Structure of the dust layer and middle-upper clouds}

Figure 9 shows the time-altitude cross-sections of the backscattering and depolarization ratios over Aksu on April 11-21, 2002. On April 11-12, 


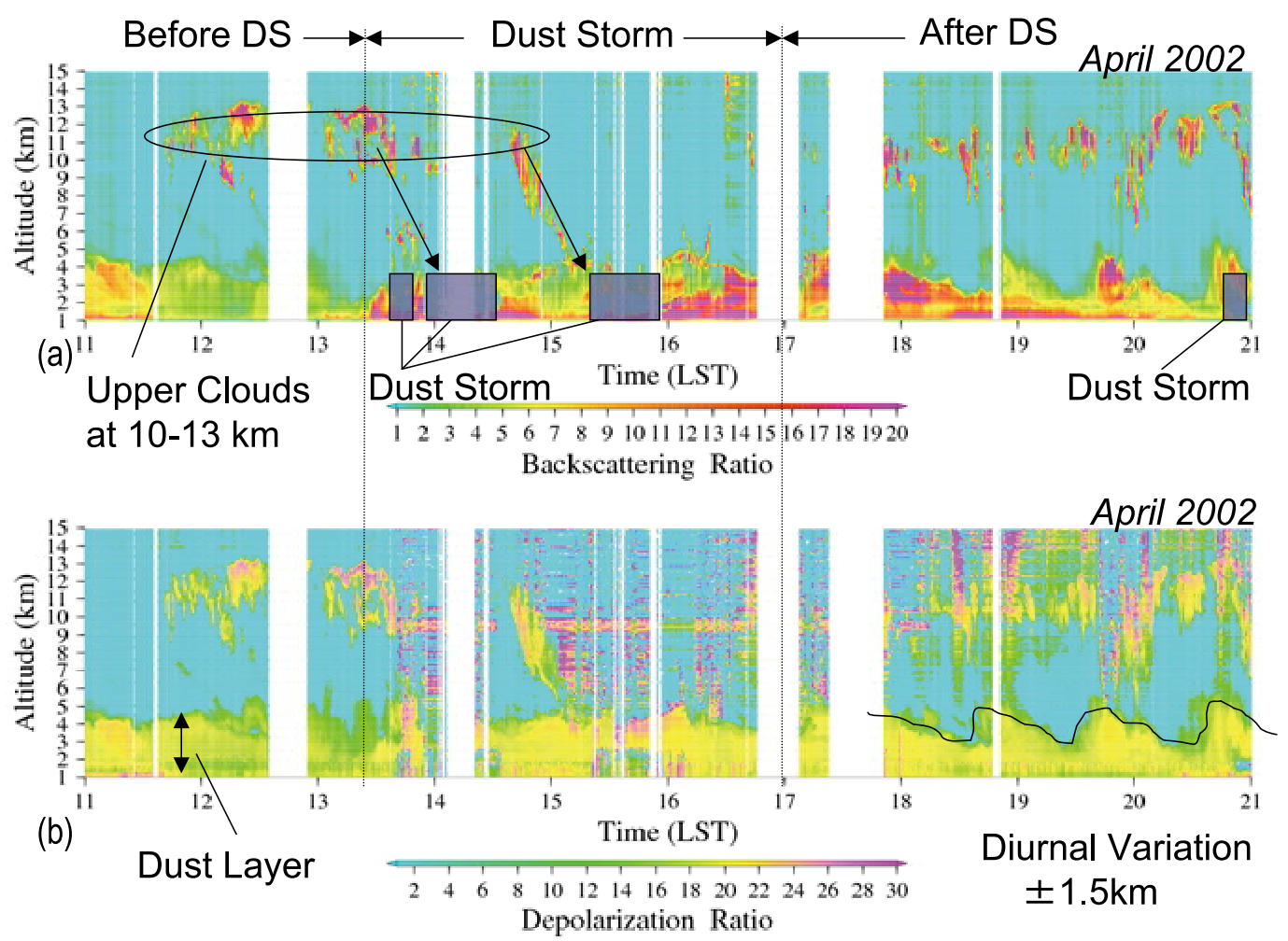

Fig. 9. Time-altitude cross-sections of backscattering ratio (a) and depolarization ratio (b) over Aksu on April 11-21, 2002. The two color scales indicate the values of the backscattering and depolarization ratios. The masked areas in Fig. 9a and the reddish zones in Fig. 9b are noise. The observation period is divided into three stages: before, during, and after the dust storm. Characteristic phenomena such as upper clouds, the dust layer and its diurnal variation are indicated in the figure.

there was a background dust layer from the surface to $3-4 \mathrm{~km}$. The backscattering was $4-8$, and the depolarization ratio was $8-10 \%$. Upper clouds frequently appeared at an altitude of $10-13 \mathrm{~km}$, which were observed every spring from 2002 and 2004 (Tsunematsu et al. 2005a). The upper clouds over Aksu may correspond to the high mountains (Tianshan Mountains and Pamir Plateau). It seems that these upper clouds descended from about an altitude of $12 \mathrm{~km}$ to an altitude of few kilometers on April 13-15. This phenomenon shows the passage of the trough with frontal clouds. This led to the onset of a strong dust storm at the surface. Figure 10 is the time-altitude changes that occurred during this process. This figure clearly shows the structure of the frontal surface with clouds. The frontal clouds descended from $12 \mathrm{~km}$ to near the surface during the period of time that lasted from the evening of April 14 to noon on April 15. At the same time, the dust layer height increased from about $3 \mathrm{~km}$ to $5 \mathrm{~km}$.

During the dust storm, surface visibility was less than $1 \mathrm{~km}$, as mentioned in the previous section. From Fig. 9a, it can be seen that the dust layer developed from the surface to $4-5.5 \mathrm{~km}$. This region had a backscattering ratio of more the 20 , which is shown by the reddish zone in the figure. The large amount of dust led to a significant absorption of the laser beam. Thus, lidar observations were impossible for several hours. The shaded areas in Fig. 9a and reddish zones in Fig. $9 \mathrm{~b}$ represent this noise.

The depolarization ratio, $D(z)$, is a good indicator of the dust layer. Mineral dusts have high values of $D(z)$ due to their non-sphericality. The depolarization ratio shows the structure of the dust layer more clearly than the backscattering ratio (Fig. 9b). During the dust storm, a typical depolarization ratio of the dust layer was $\sim 23 \%$. 


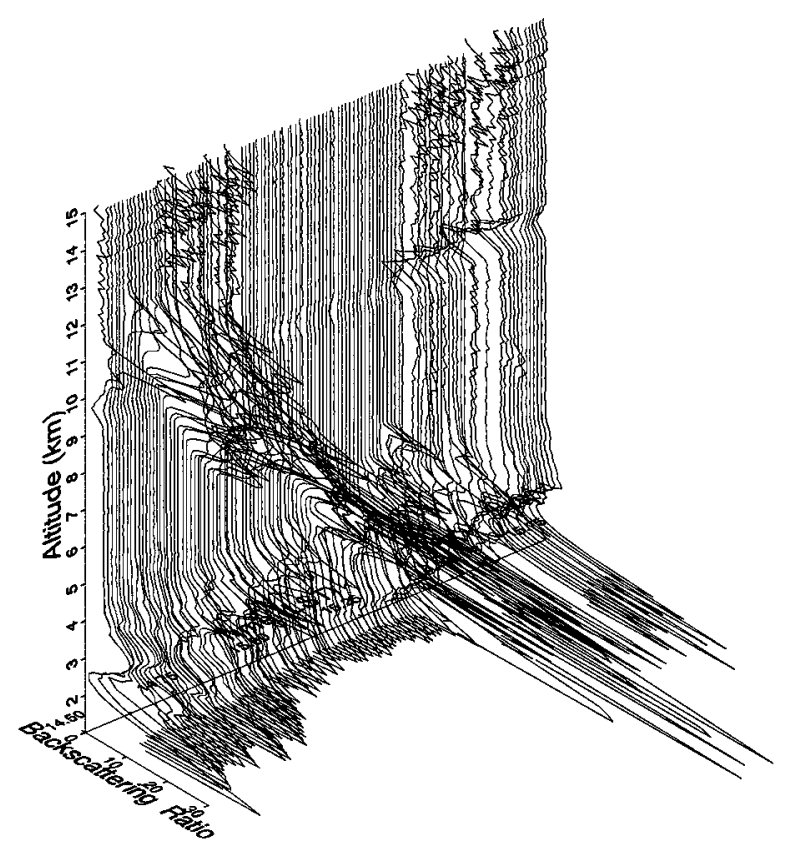

Fig. 10. Time - altitude change in the descending upper clouds over Aksu during the passage of the dust storm on April 14-15, 2002. Backscattering ratio represents the upper clouds from $4-15 \mathrm{~km}$ and the dust layer from $3-5 \mathrm{~km}$.

After the dust storms (AD), during April 18 and 20, as seen in Fig. 9b, a diurnal variation at the top of the dust layer with an amplitude of 1.5 $\mathrm{km}$ was present. To examine this diurnal variation, the maximum height of the dust layer at midnight, and the minimum height in afternoon (about 1500 LST) were noted. Generally speaking, a mixed layer develops during the daytime. The mixed layer transports the dust from the surface to the upper heights by turbulence and convection. Of note, these results are opposite to the usual mixed layer model found in other places in the world (see Fig. 9). The characteristic diurnal variation may reflect the effect of the meso-scale circulation in the Tarim Basin or in the mountain -valley wind system in the Tianshan Mountains. During the daytime, the descending flow over Aksu, which is the counterpart of the mountain -valley wind system, may suppress the expected behavior of the dust layer (Tsunematsu et al. 2005a).

\subsection{Estimation of the backscattering ratio during the dust storm}

The relationship between the backscattering ratio and the range corrected backscattering signal is derived from Eq. (1)-(4) as follows:

$$
\begin{aligned}
z^{2} P(z)=K \beta_{m}(z) R(z) & \\
\exp \left[-2 \int_{0}^{z}\{\right. & S_{1} \beta_{m}\left(z^{\prime}\right) R\left(z^{\prime}\right) \\
& \left.\left.+\left(\frac{8 \pi}{3}-S_{1}\right) \beta_{m}\left(z^{\prime}\right)\right\} d z^{\prime}\right]
\end{aligned}
$$

The lidar system has two telescopes, $200 \mathrm{~mm}$ and $350 \mathrm{~mm}$, of which the smaller one is coaxial to the laser beam. If we assume the uniformity of the aerosol distribution between the observation window of the lidar container and the lowest observation height of $187 \mathrm{~m}$, Eq. (10) at the lowest height $(187 \mathrm{~m})$ reduces to:

$$
\begin{aligned}
& z_{1}^{2} P\left(z_{1}\right) \sim a_{1} R\left(z_{1}\right) \exp \left(-a_{2} R\left(z_{1}\right)\right) \\
& a_{1}=K \beta_{m 0} \exp \left(-2 \int_{0}^{z_{1}}\left(\frac{8 \pi}{3}-S_{1}\right) \beta_{m}\left(z^{\prime}\right) d z^{\prime}\right) \\
& a_{2}=2 S_{1} \beta_{m 0} \Delta z \sim 0.018
\end{aligned}
$$

where $z_{1}$ is $187 \mathrm{~m}$, and $\beta_{m 0}=1.395 \times 10^{-6} \mathrm{~m}^{-1} \mathrm{sr}^{-1}$.

If the experimental data obtained on fine weather days verifies Eq. (11), then this equation can be used for data obtained during a dust storm event. The range corrected backscattering signals are plotted against the backscattering ratio in Fig. 11. The experimental line need to verify Eq. (11) is also shown in Fig. 11. Equation (11) was used for a severe dust case, in which a dense dust layer spread up to the altitude of about $4 \mathrm{~km}$, since the attenuation of the laser beam by such dust layer avoided us to normalize the range-corrected signal at an aerosol free height in the iteration mentioned above.

Figure 12 shows the time series of $R(187 \mathrm{~m})$, the backscattering ratio at $187 \mathrm{~m}$ during the dust storm on April 11-21. The value of $R(187 \mathrm{~m})$ represents the amount of dust near the ground. During April 11-12, the backscattering ratio had a value less than 10; after the dust storm on April 13, the ratio increased to 25. During April 18-20, the backscattering ratio decreased gradually. On April 21, another dust storm occurred.

In order to check the estimates of $R(187 \mathrm{~m})$, the reciprocal of the visibility is plotted in the same figure. The relationship between the visibility $V(m)$ and extinction coefficient $\sigma$ is as follows:

$$
\sigma=3.9 / V
$$




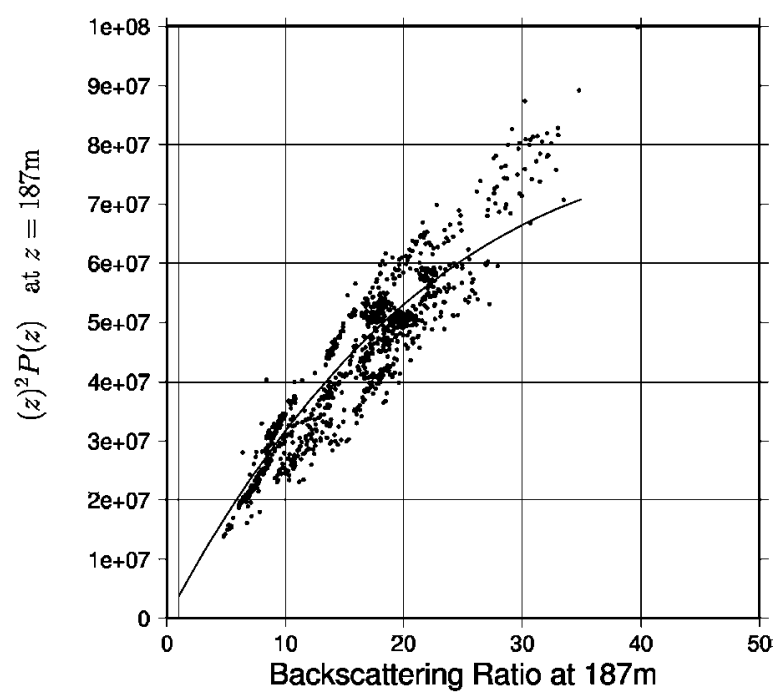

Fig. 11. Range corrected lidar signal versus backscattering ratio at $187 \mathrm{~m}$. Equation (10) is shown in the figure.

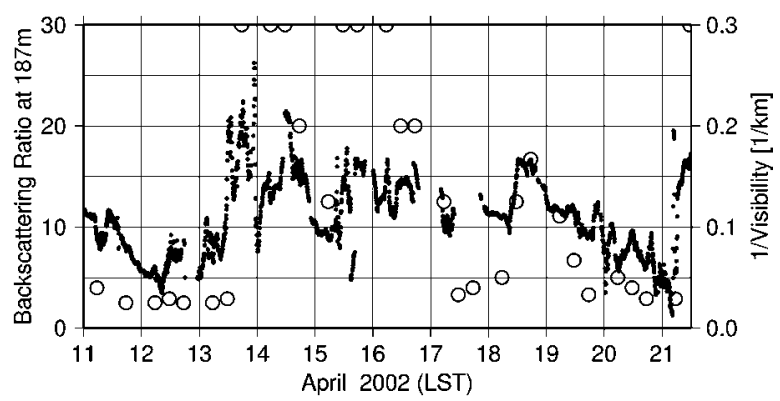

Fig. 12. Estimated backscattering ratio at $187 \mathrm{~m}(\mathrm{O})$ and the reciprocal of the visibility (○) during April 11 and 21, 2002.

where $V$ is visibility (Fleagle and Businger 1980). It coincides with the time series of $R(187 m)$ except extremely dusty cases.

Figure 13 shows the relationship between the backscattering ratio at $187 \mathrm{~m}$ and the wind speed at $10 \mathrm{~m}$. The data are classified into three stages: before the dust storm (BD), during the dust storm (DS), and after the dust storm (AD). Before the dust storm and during the dust storm, the backscattering ratio increases with an increase in the wind speed, but after the dust storm, the backscattering ratio has a high value even for a weak wind. This implies that dust continued to float over the Taklimakan Desert after the dust storm possibly because of the closed topography of the Taklimak-

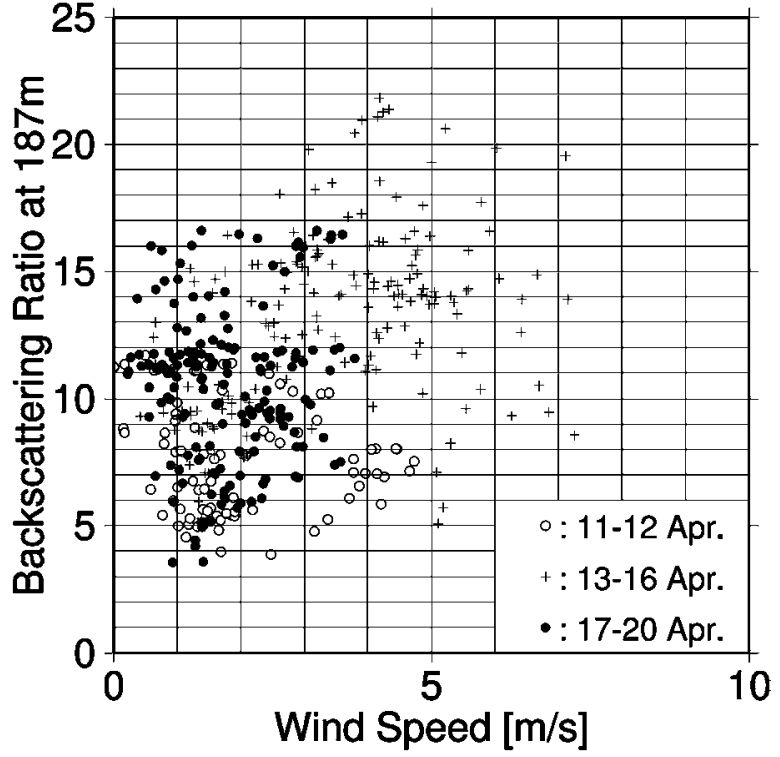

Fig. 13. The relationship between the backscattering ratio at $187 \mathrm{~m}$ and the wind speed at $10 \mathrm{~m}$. Symbols $\bigcirc$ : before the dust storm (11-12 Apri), +: during the dust storm (13-16 April), and $\mathbf{O}$ : after the dust storm (17-20 April).

an Desert.

\subsection{Diurnal variation of the dust layer and the dust removal process}

The lidar signals at different heights suggest two types of processes of the dust with a size distribution (coarse and fine particles).

Figure 14 shows a time series of the backscattering ratio at heights of $0.187,1,2,3,4$, and 5 $\mathrm{km}$ from April 18-21, 2002. The behavior of the lidar signals at the lower heights (187 $\mathrm{m}$ and 1 $\mathrm{km}$ ) appears to be different from that at the higher heights (above $2 \mathrm{~km}$ ). The lidar signals at the lower heights gradually or linearly decreased during April 18-20. Yabuki et al. (2005) showed that the size distribution of aerosol at a height of $7 \mathrm{~m}$ at Aksu in spring is unimodal with a maximum concentration in the region of 3.3-7.0 $\mathrm{\mu m}$, with coarse particles accounting for more than 95\% of the total aerosols. This can be explained as follows; the gradual decrease of the lidar signals at the lower height (less than $2 \mathrm{~km}$ ) indicates the gravitational settling of the relatively large size dust (coarse particles) near the ground, which were directly lifted up into the atmosphere during 


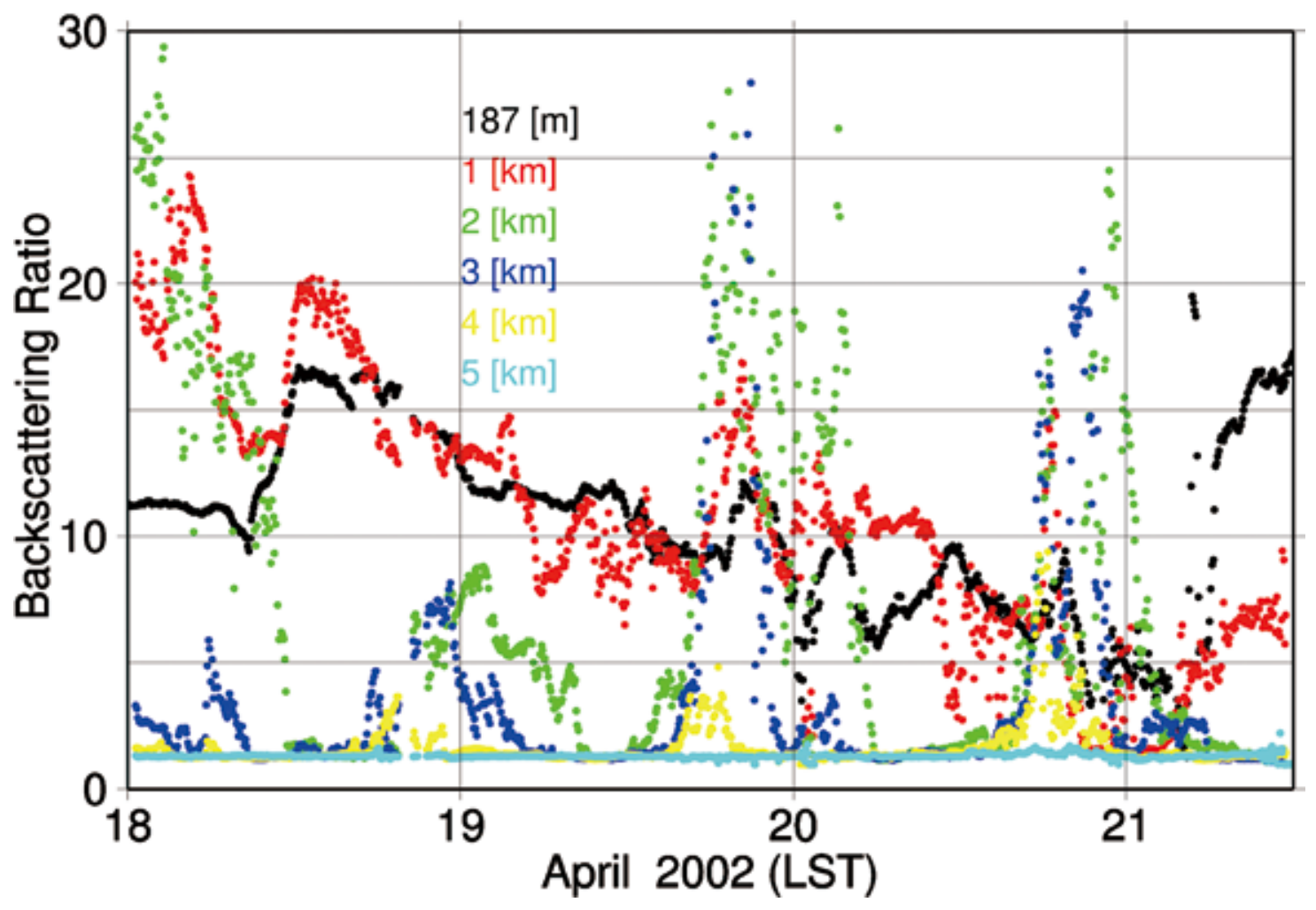

Fig. 14. Time series of the backscattering ratios at heights of $0.187,1,2,3,4$ and $5 \mathrm{~km}$ on April 18-21, 2002. Symbols $\bigcirc: 187 \mathrm{~m}, \bigcirc: 1 \mathrm{~km}, \bigcirc: 2 \mathrm{~km}, \bigcirc: 3 \mathrm{~km}, \bigcirc: 4 \mathrm{~km}, \bigcirc: 5 \mathrm{~km}$.

the dust storm.

On the other hand, the lidar signals at $2-4 \mathrm{~km}$ show a diurnal variation with spike-like peaks from evening to midnight. Tsunematsu et al. (2005a) showed that synoptic-scale airflows over the Taklimakan Desert and the mountain-valley wind system between the Tianshan Mountains and the Desert formed a large local circulation over the north of the Desert. Tsunematsu et al. (2005b) made the diffusion experiment on the dust in the Taklimakan desert during the dust storm in March 2004. According to Jacobson (2002), dust particles larger than $10 \mu \mathrm{m}$ fall out rapidly, but those between 1 and $10 \mu \mathrm{m}$ can stay in the atmosphere for days to weeks or longer, depending on the height to which they are originally lifted. The recent research suggests that the dust between 1 and $10 \mu \mathrm{m}$ or so, lifted up in other places, could be transported by meso-scale local circulations over Aksu (Tsunematsu et al. 2005a).

The dust above $\sim 5 \mathrm{~km}$ can be said to be a background tropospheric aerosol over the Taklimakan
Desert. There is no diurnal peak at a height of $5 \mathrm{~km}$. This suggests that the vertical transport of the dust was limited to $4 \mathrm{~km}$. Thus, the temperature inversion layer located at $\sim 4 \mathrm{~km}$ may be the upper limit of the dust layer. We analyzed the radiosonde data at Aksu during the IOP. But, we could not identify the temperature inversion layer because of the low resolution of height of the radiosonde data during the IOP. One of the radiosonde data in March 2003 shows a coincidence between the temperature inversion layer and the dust layer (Fig. 15), which supports the existence of the capping temperature inversion layer (Garratt 1992).

\section{Conclusion}

As part of the Japan-China Joint Studies on Origin and Transport of Aeolian Dust and its Impact on Climate (ADEC) group, we developed a new lidar that was used to study the vertical structure of the dust layer over the Taklimakan Desert. In April 2002, the lidar in Aksu was used to successfully observe severe dust storms. 

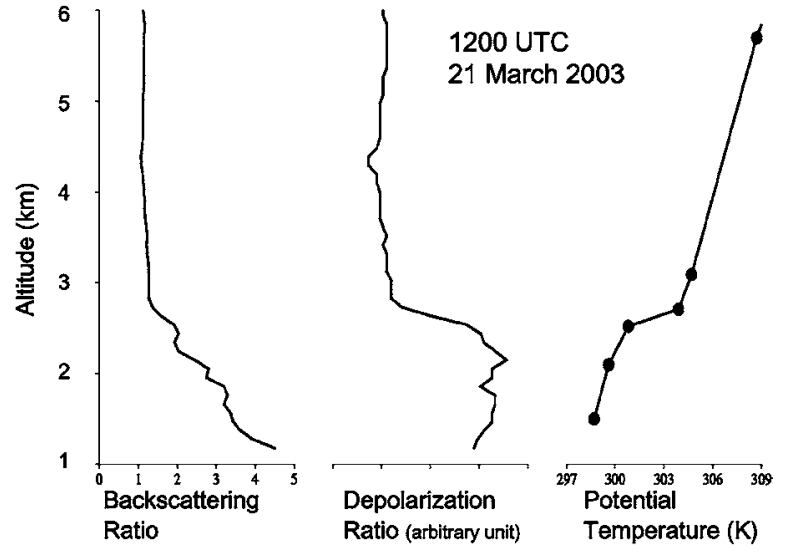

Fig. 15. Vertical profiles of backscattering ratio, depolarization ratio and potential temperature over Aksu at 1200 UTC on 21 March 2003.

The main results can be summarized as follows:

(1) Before the dust storm (April 11-12): The sky was clear with a visibility of $40 \mathrm{~km}$. The dust layer had a height of 3-4 km, the backscattering ratio was $4-8$, and the depolarization was $8-10 \%$. Upper clouds frequently appeared at a height of $10-13 \mathrm{~km}$, which may correspond to the surrounding high mountains and plateaus.

(2) During the dust storm (April 13-16): On April 13, the upper clouds descended to the ground resulting in a dust storm at 1430 LST. A strong easterly wind blew with a peak surface wind speed of over $6 \mathrm{~m} \mathrm{~s}^{-1}$. The visibility was less than $1 \mathrm{~km}$. The dust storm continued for 4 days. The dense dust layer developed from the ground up to $5.5 \mathrm{~km}$. The backscattering ratio was 20 or more, and the depolarization ratio was $15-25 \%$.

(3) After the dust storm (April 17-20): A diurnal variation in the top of the dust layer was observed. The lidar signals at lower heights (less than the $2 \mathrm{~km}$ ) gradually decreased during the post-dust storm period. This result indicates that gravitational settling of the relatively large sized dust (coarse particles with a diameter of $10 \mu \mathrm{m}$ or more) occurs near the ground. On the other hand, lidar signals at $2-4 \mathrm{~km}$ had a clear diurnal variation with spike-like peaks from evening to midnight. These peaks suggest that the advection of the dust between 1 and $10 \mu \mathrm{m}$ or so picked up in other location is due to the local circulation that occurs in the Tianshan Mountains and Tarim Basin.

(4) The lidar observation during the dust storm was impossible for several hours due to the absorption of the laser beam by heavy dust. In this study, we estimated the backscattering ratio at the lowest height during the dust storm by directly solving the lidar equation.

The lidar observations show that the dust layer and its diurnal variation over the Taklimakan Desert may be influenced by meso-scale circulations. A numerical experiment will be needed to investigate the advection of the dust by mesoscale circulations.

\section{Acknowledgement}

This study was performed through the project of Aeolian Dust Experiment on Climate impact (ADEC) supported by the Special Coordination Funds for Promoting Science and Technology of MEXT and the Japanese Government. We appreciate the cooperation of Prof. Wei Wenshou of Institute of Desert Meteorology, CMA and Prof. Shi Gang-Yu of Institute of Atmospheric Physics, CAS. We would like to thank Dr. T. Sakai for his valuable advice on the lidar observation and data processing, Dr. M. Mikami of Meteorological Research Institute, JMA for providing the AWS data, and Dr. S. Yabuki of RIKEN for the aerosol sampling.

\section{References}

Duce, R.A., C.K. Unni, B.J. Ray, J.M. Prospero, and J.T. Merrill, 1980: Long-range atmospheric transport of soil dust from Asia to the tropical North Pacific: Temporal variability. Science, 209, 15221524.

Fleagle, R.G. and J.A. Businger, 1980: An introduction to atmospheric physics, Academic Press, $432 \mathrm{pp}$.

Garratt, J.R., 1992: The atmospheric boundary layer, Cambridge University Press, 3-4.

Grell, G.A., J. Dudhia, and D.R. Stauffer, 1995: A description of the fifth generation Penn State/ NCAR mesoscale model (MM5), NCAR Technical report.

Ismail, S., E.V. Browel, R.A. Ferrare, S.A. Kooi, M.B. Clayton, V.G. Brackett, and P.B. Russell, 2000: LASE measurements of aerosol and water vapor profiles during TARFOX. J. Geophs. Res., 105(D8), 9903-9916.

Iwasaka, Y., H. Minoura, and K. Nagaya, 1983: The 
transport and spatial scales of Asian dust-storm clouds: a case study of the dust-storm event of April 1979. Tellus, 35B, 189-196.

Iwasaka, Y., M. Yamato, R. Imasu, and A. One, 1988: Transport of dust (KOSA) particles; importance of weak KOSA events on the geochemical cycle of soil particles. Tellus, 40B, 494-503.

Iwasaka, Y., G.-Y. Shi, M. Yamada, A. Matsuki, D. Trochkine, Y.S. Kim, D. Zhang, T. Nagatani, T. Shibata, M. Nagatani, H. Nakata, Z. Shen, G. Li, and B. Chen, 2003: Importance of dust particles in the free troposphere over the Taklamakan Desert: Electron microscopic experiments of particles collected with a balloon-borne particle impactor at Dunhuang, China. J. Geophs. Res., 108(D23), doi:10.1029/2002D003270.

Jacobson, M.Z., 2002: Atmospheric pollution-History, science, and regulation. Cambridge University Press, 121-122.

Kai, K., Y. Okada, O. Uchino, I. Tabata, H. Nakamura, T. Takasugi, and Y. Nikaidou, 1988: Lidar observation and numerical simulation of a Kosa (Asian Dust) over Tsukuba, Japan during the spring of 1986. J. Meteor. Soc. Japan, 66, 457-472.

Kai, K., S. Hu, H. Zhou, T. Yasojima, B. Xu, T. Nagai, and M. Abo, 2002: Development of a new lidar for measuring the aeolian dust originated from the Taklamakan Desert: test observation at Tsukuba, Japan. J. arid Land Studies, 11(4), 321 -325 .

Kurosaki, Y. and M. Mikami, 2003: Recent frequent dust events and their relation to surface wind in East Asia. Geophys. Res. Lett., 30(14), 1736, doi: 10.1029/2003GL017261.

Mikami, M., G.-Y. Shi, I. Uno, S. Yabuki, Y. Iwasaka, M. Yasui, T. Aoki, Y. Tanaka, Y. Kurosaki, K. Masuda, A. Uchiyama, A. Matsuki, T. Sakai, T. Takemi, M. Nakawo, N. Seino, M. Ishizuka, S. Satake, K. Fujita, Y. Hara, K. Kai, S. Kanayama, M. Hayashi, M. Du, Y. Kanai, Y. Yamada, X.-Y. Zhang, Z. Shen, H. Zhou, O. Abe, T. Nagai, Y. Tsutsumi, M. Chiba, and J. Suzuki, 2005: Aeolian dust experiment on climate impact: An Overview of Japan-China joint project ADEC. Global Planetary Change, 52, 142-172.

Sakai, T., T. Shibata, and Y. Iwasaka, 1997: Relative humidity, backscattering ratio and depolarization ratio as derived from Raman lidar observations. J. Meteor. Soc. Japan, 75, 1179-1185.

Seino, N., Sasaki, A. Yamamoto, M. Mikami, and H.
Zhou, 2005: Numerical simulation of mesoscale circulations in the Tarim Basin associated with dust events. J. Meteor. Soc. Japan, 83A, 205218.

Spinhirne, J.D., S.P. Palm, W.D. Hart, D.L. Hlavka, and E.J. Welton, 2005: Cloud and aerosol measurements from GLAS: overview and initial results. Geophys. Res. Lett., 32, L22S03, doi:10. 1029/2005GL023507.

Tsunematsu, N., 2005: Observed dust storm in the Taklimakan Desert on April 13, 2002. SOLA, 1, 21-24.

Tsunematsu, N., K. Kai, and T. Matsumoto, 2005a: The influence of synoptic-scale air flow and local circulation on the dust layer height in the north of the Taklimakan Desert. Water, Air, and Soil Pollution: Focus, 5(3-6), 175-193.

Tsunematsu, N., T. Sato, F. Kimura, K. Kai, Y. Kurosaki, T. Nagai, and H. Zhou, M. Mikami, 2005b: Extensive dust outbreaks following the morning inversion breakup in the Taklimakan Desert. J. Geophys. Res., 110(D21207), doi:10.1029/ 2005JD005994.

UNCCD (United Nations Convention to Combat Desertification), 2001: Global Alarm: Dust and sandstorms from the world's drylands. $318 \mathrm{p}$. $\mathrm{http}: / /$ www.unccd.int/publicinfo/duststorms/ menu.php

Uno, I., K. Harada, S. Satake, Y. Hara, and Z. Wang, 2005: Meteorological characteristics and dust distribution of the Tarim Basin simulated by the nesting RAMS/CFORS dust model. J. Meteor. Soc. Japan, 83A, 219-239.

Vaugham, M., S. Young, D. Windker, K. Powell, and A. Omar, 2004: Fully automated analysis of spacebased lidar data: an overview of the CALIPSO retrieval algorithms and data products. Proc. SPIE, 5575, 16-30.

Yabuki, S., M. Mikami, Y. Nakamura, S Kanayama, F. Fu, M. Liu, and H. Zhou, 2005: The characteristics of atmospheric aerosol at Aksu, an Asian dust source region of North-West China: A summary of observations over the three years from March 2001 to April 2004. J. Meteor. Soc. Japan, 83A, 45-72.

Yasui, M., J. Zhou, L. Liu, T. Itabe, K. Mizutani, and T. Aoki, 2005: Vertical profiles of Aeolian dust in a desert atmosphere observed using lidar in Shapotou, China. J. Meteor. Soc. Japan, 83A, 149-171. 